\title{
Minimal Baseline Fetal Heart Rate Variability
}

National Cancer Institute

\section{Source}

National Cancer Institute. Minimal Baseline Fetal Heart Rate Variability. NCI Thesaurus.

Code C111767.

A baseline fetal heart rate with a detectable amplitude range that is greater than undetectable but less than or equal to five beats per minute. 